\title{
Backward conditioning of taste aversions in rats using cyclophosphamide as the US
}

\author{
LEWIS M. BARKER, E. MARTIN SUAREZ, and DON GRAY \\ Baylor University, Waco, Texas 76703
}

\begin{abstract}
Conditioned taste aversion was demonstrated to result from a US-CS, or "backward," conditioning procedure using a $75-\mathrm{mg} / \mathrm{kg}$ cyclophosphamide injection as the US. The magnitude and resistance to extinction of the conditioned taste aversion was found to decrease monotonically when the US-CS ISI was systematically varied from $1.0 \mathrm{~min}$ to $4 \mathrm{~h}$. In this respect and in the inconclusive nature of the signs of sickness following US administration, cyclophosphamide appears to act similarly to ionizing radiation in conditioning taste aversions. It was argued that these results reflect truly associative, not pseudoconditioned, avoidance responses.
\end{abstract}

The phenomenon of conditioning taste aversions over CS-US delay intervals of several hours is well established (Smith \& Roll, 1966; Revusky, 1968; Nachman, 1970; Barker \& Smith, 1974). Taste aversions produced by US-CS, or "backward," procedures have also been reported, but have not yet been incorporated into the bait-shyness literature. Scarborough, Whaley, and Rogers (1964) and Morris and Smith (1964) reported conditioned aversion to saccharin solutions resulting from similar procedures in which rats were first exposed to ionizing radiation (US) and then allowed saccharin (CS) following US-CS delays of several hours. In both studies, this conditioning was attributed to the contiguous pairing of the taste CS with a prolonged adverse physiological disturbance initiated by the X-ray exposure. In a recent comparison of the unconditioned stimulus properties of ionizing radiation and lithium chloride ( $\mathrm{LiCl})$, a 100-roentgen exposure was found to be effective in conditioning taste aversions over a 6-h US-CS interval, whereas a $2 \%$ body weight injection of $0.15 \mathrm{M} \mathrm{LiCl}$ was ineffective at a $1 / 2$-h US-CS interval (Barker \& Smith, 1974). Because the rats treated with this dosage of $\mathrm{LiCl}$ were visibly sick $1 / 2 \mathrm{~h}$ postinjection, the taste CS was presumably contiguous with the LiCl-induced sickness, but failed to result in a conditioned taste aversion. It was further argued that these differences in conditioning using US-CS procedures could not be entirely attributed to differences in the "strength" or "intensity" of the two USs, since the dosages used produced relatively comparable aversions following CS-US delays of several hours.

The present experiment was an investigation of the unconditioned stimulus properties of cyclophosphamide (Cytoxan ${ }^{R}$ ), a nitrogen mustard derivative, in a US-CS taste aversion paradigm. Cyclophosphamide has been used in cancer chemotherapy because of its radiomimetic properties; e.g., it is "... cytoxic to all tissues, especially rapidly renewing tissues such as intestinal mucosa, corneal epithelium, germinal tissues, lymphatic and hematopoietic tissues [Cutting, 1969, p. 134]." The signs of severe cyclophosphamide toxicosis in man includes diarrhea, anorexia, alopecia (loss of hair), and bone marrow depression (Fairley \& Sinister, 1965), and muscular paralysis and convulsions (Cutting, 1969). In addition, commonly exhibited symptoms of patients undergoing cancer chemotherapy are abdominal pain and nausea. Cyclophosphamide has seen increasing usage in producing taste aversions (Garcia, Ervin, \& Koelling, 1967; Dragoin, 1971; Garcia, McGowan, \& Green, 1972; Etscorn, 1973), and is implied to have US properties that are similar to ionizing radiation, $\mathrm{LiCl}$, and apomorphine. Simply stated, in this experiment we wanted to know if cyclophosphamide acted like ionizing radiation (and unlike $\mathrm{LiCl}$ ) in conditioning taste aversions over US-CS delay intervals of several hours.

\section{METHOD}

\section{Subjects}

The 55 female Holtzman albino rats $(220-285 \mathrm{~g})$ used in this experiment were individually housed in Hoeltge cages, where Purina rat chow was available ad lib for the duration of the experiment. The colony was on a 12-h light-dark cycle, with the lights on from $0700-1900 \mathrm{~h}$.

\section{Apparatus}

The rats were tested in round plastic cages $24 \mathrm{~cm}$ in diam by $21 \mathrm{~cm}$ high, with wire mesh floors. A 100-ml graduated Richter tube was attached to the side of each cage.

\section{Procedure}

All rats were habituated to drink from the Richter tubes by placing them on water deprivation and allowing them $10 \mathrm{~min}$ access to water for 4-5 days prior to treatment. The mean intake $( \pm 0.5 \mathrm{ml})$ of tap water for the last 2 habituation days was determined for each $\mathrm{S}$. These scores were rank ordered and the Ss were placed in groups, so that the mean baseline water intakes for all groups were approximately equal. On treatment day all rats were injected IP with $75 \mathrm{mg} / \mathrm{kg}$ cyclophosphamide (in normal saline) and, after different time delays, were allowed $10 \mathrm{~min}$ access to either $0.25 \%$ sodium saccharin solution or tap water. The US-CS interstimulus intervals used were $1,30,60$, 120 , and $240 \mathrm{~min}$; the group designations, therefore, were 1-sacc, 30-sacc, and 60-sacc $(\mathrm{N}=10$ per group), 120-sacc, 240 -sacc, $1-\mathrm{H}_{2} \mathrm{O}, 30-\mathrm{H}_{2} \mathrm{O}$, and $60-\mathrm{H}_{2} \mathrm{O}(\mathrm{N}=5$ per group $)$.

All groups had 10 min water on Days 2-3 following treatment 


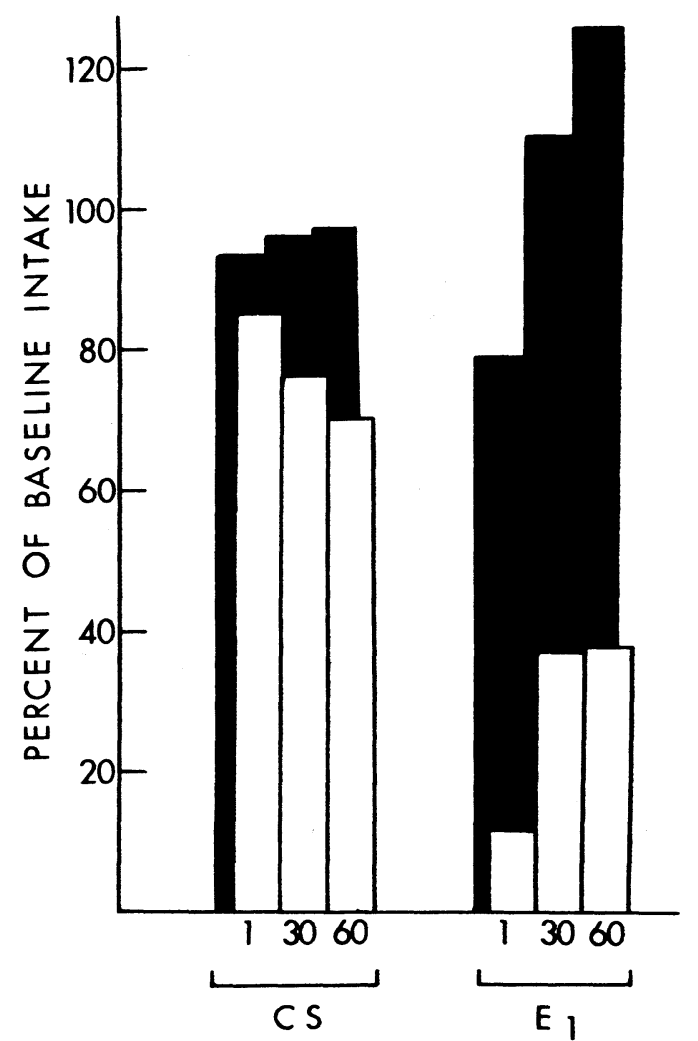

Fig. 1. Mean fluid intake in 10-min periods on treatment day (CS) and the first extinction test $\left(E_{1}\right)$ as a function of the US-CS interval for the 1-, 30-, and 60-min groups having either a $0.25 \%$ saccharin CS (white bars) or water CS (black bars).

and again on Days 5-6, 8-9, 11-12, and 14-15. On Days 4, 7, 10 , 13 , and 16, all groups had 10 min access to $0.25 \%$ saccharin solution, and these saccharin days were designated Extinction Tests 1-5.

\section{RESULTS}

Marked individual differences in the overt signs of cyclophosphamide toxicosis were noted in the present experiment and in unpublished experiments using this same dosage. In comparison to saline injected controls, there was an absence of an observable response in approximately $30 \%-40 \%$ of the rats, a decreased motor activity (e.g., reduced grooming, rearing, and "sniffing") in about half of the rats, and a quite acute locomotor disability in $10 \%-15 \%$. In this latter group, the rats would characteristically drag both hind limbs as they crawled with their fore limbs. Those rats showing decreased motor activity and/or the locomotor disability evidenced these signs $20-40$ min postinjection and were essentially normal $30-60$ min later. No relationship was found between the presence or absence of these overt signs of cyclophosphamide toxicosis and the type of fluid consumed, the time interval preceding fluid consumption, or the subsequent conditioning effect.

The mean fluid consumption (expressed as percent of baseline intake) on treatment day and the first extinction test $\left(\mathrm{E}_{1}\right)$ for the 1-, 30-, and 60-sacc and 1-, 30-, and $60-\mathrm{H}_{2} \mathrm{O}$ groups are presented in Fig. 1. Initially, the CS intakes of 1-sacc with $1-\mathrm{H}_{2} \mathrm{O}, 30$-sacc with $30-\mathrm{H}_{2} \mathrm{O}$, and 60 -sacc with $60-\mathrm{H}_{2} \mathrm{O}$ were compared. Only the 60-sacc group differed significantly from the $60-\mathrm{H}_{2} \mathrm{O}$ group ( $\mathrm{t}=3.49, \mathrm{df}=9, \mathrm{p}<.005$, two-tailed $)$. In similar comparisons of the 1-, 30-, and 60-sacc groups with their respective water control groups on $\mathrm{E}_{1}$, all saccharin CS groups were found to have consumed significantly less saccharin than did the water CS groups $(t=6.08,15.37$, and 9.08 , respectively, all $\mathrm{dfs}=9$, all ps $<.005$, one-tailed).

Figure 2 traces the course of extinction of the conditioned saccharin aversion for the five US-CS groups whose CS was saccharin. A Type SPF 5.6 unweighted means analysis of variance with repeated measures (Kirk, 1968) was used to evaluate these extinction data. The US-CS interval $(F=7.173$, $d f=4 / 35)$, extinction test trials $(\mathrm{F}=59.468, \mathrm{df}=5 / 175)$, and their interaction $(F=4.937, \mathrm{df}=20 / 75)$ were all significant beyond the .01 level of confidence. Because of the repeated measures design, a Geisser-Greenhouse conservative F-test adjustment was employed for all $\mathrm{F}$ tests (Kirk, 1968). In tests of simple main effects, the US-CS interval was significant only on Extinction Tests $E_{1}-E_{4}$ ( $p<\alpha=.0083$ ); the amount consumed by the five US-CS groups was not significantly different on either the treatment day or the last extinction test trial, $E_{5}$.

Tests among the means of the five US-CS groups on Extinction Tests 1.4 were made using Tukey's HSD statistic for pairwise comparisons (Kirk, 1968). The

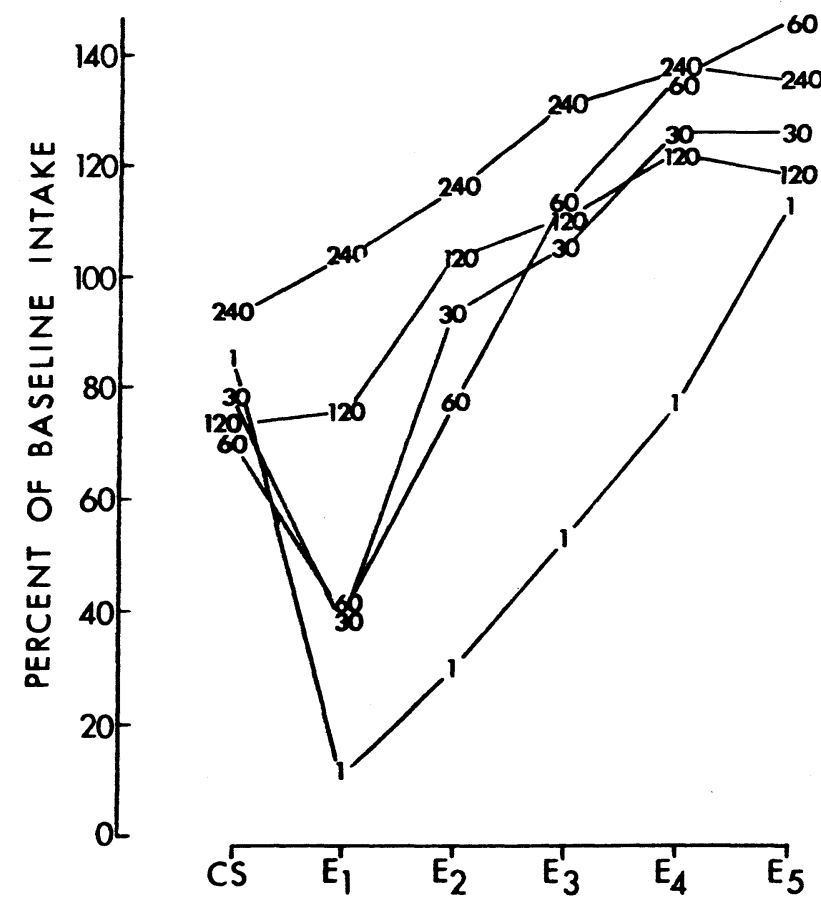

Fig. 2. Mean fluid intake on treatment day (CS) and five successive extinction tests $\left(E_{1}-E_{5}\right)$ for the 1-, 30, 60-, 120, and 240 -min US-CS groups whose CS was $0.25 \%$ saccharin. 
results of these tests revealed that on $E_{1}$ the 1 -sacc, 30-sacc, and 60-sacc groups were significantly different from the 240-sacc group. On $E_{2}-E_{4}$ only the 1-sacc group was different from the remaining US-CS groups.

\section{CONCLUSION AND DISCUSSION}

It was demonstrated in this experiment that a conditioned taste aversion could result from the pairing of a saccharin CS that followed a $75-\mathrm{mg} / \mathrm{kg}$ IP administration of cyclophosphamide by as much as $60 \mathrm{~min}$. In this respect, the unconditioned stimulus properties of cyclophosphamide in a taste aversion conditioning paradigm clearly resemble ionizing radiation and not $\mathrm{LiCl}$. In addition, the apparent lack of a systematic relationship between the immediate signs of cyclophosphamide intoxication and the subsequent magnitude of conditioned taste aversion is similar to radiation-induced taste aversions and dissimilar to LiCl-induced aversions (Barker \& Smith, 1974). This finding lends support to the contention of Brown and Glusman (1971) and Berger (1972) that observable "sickness" is not a necessary precondition in the establishment of taste aversions.

Less saccharin than water was consumed in the postinjection CS period, and this finding is in agreement with both Garcia et al (1972), who also employed cyclophosphamide, and Barker and Smith (1974), who used $\mathrm{LiCl}$ as the toxic agent. It is important to note that saccharin consumption in the CS period is not a good predictor of the subsequent magnitude of conditioned aversion (cf. Fig. 1). The proximity of the CS to the injection appears to determine both aversion magnitude and resistance to extinction (cf. Fig. 2).

The groups having a water CS tasted saccharin for the first time on $\mathrm{E}_{1}$, the first extinction test. These water CS groups should be demonstrating "illness-induced neophobia" on $\mathrm{E}_{1}$; e.g., they were animals recently made sick, then subsequently allowed access to a novel taste (cf. Rzoska, 1953; Rozin, 1968; Nachman, 1970). Relative to their water baselines, however, only the $1-\mathrm{H}_{2} \mathrm{O}$ group (and not the $30-\mathrm{H}_{2} \mathrm{O}$ or $60-\mathrm{H}_{2} \mathrm{O}$ groups) evidenced a reduced saccharin intake on $\mathrm{E}_{1}$. As was suggested previously, the magnitude of illness-induced neophobia may be in part accounted for by proximity of sickness to the water CS period, suggesting a generalized "punishment of ingestion" (Barker \& Smith, 1974).

Any attempted demonstration of "backward" conditioning is subjected to considerable scrutiny, possibly because, as Razran (1971) has suggested, such conditioning violates the contingency model of stimulus sequencing. In the taste aversion conditioning paradigm, moreover, the taste stimulus (CS) and X-rays, drugs, or toxins (US) are of lengthy (quite often indeterminate) duration, which makes it exceedingly difficult to specify the precise sequencing of the CS and US. Following Razran's (1971) model of backward conditioning, it is suggested that both ionizing radiation and cyclophosphamide have sufficiently powerful US properties, such that the unconditioned response to these agents can precede and overlap in time a taste stimulus, become associated with that stimulus, and yield a conditioned avoidance of that stimulus. We are, therefore, in disagreement with the contention of Garcia et al (1972) that the reduced intake of a taste CS following a US-CS procedure reflects a "nonassociative," "pseudoconditioned" response.

\section{REFERENCES}

Barker, L. M., \& Smith, J. C. A comparison of taste aversions induced by radiation and lithium chloride in CS-US and US-CS paradigms. Journal of Comparative \& Physiological Psychology, 1974, in press.

Berger, B. D. Conditioning of food aversions by injections of psychoactive drugs. Journal of Comparative \& Physiological Psychology, 1972, 81, 21-26.

Brown, D. L., \& Glusman, M. Conditioned gustatory aversion with anesthetic and convulsic agents. Paper presented at the Psychonom ic Society meeting, St. Louis, 1971

Cutting, W. D. Handbook of pharmacology. New York: Appleton-Century-Crofts, 1969.

Dragoin, W. B. Conditioning and extinction of taste aversions with variations in the intensity of the CS and UCS in two strains of rats. Psychonomic Science, 1971, 22, 303-304.

Etscorn, F. Effects of a preferred vs a nonpreferred CS in the establishment of a taste aversion. Physiological Psychology, $1973,1,5-6$.

Fairley, G. H., \& Sinister, J. M. Cyclophosphamide. Baltimore: Williams \& Wilkins, 1965.

Garcia, J., Ervin, F. R., \& Koelling, R. A. Bait-shyness: A test for toxicity with $n=2$. Psychonomic Science, 1967, 7, 245-246.

Garcia, J., McGowan, B. K., \& Green, K. F. Biological constraints on conditioning. In A. Black and W. F. Prokasy (Eds.), Classical conditioning II: Current research and theory. New York: Appleton-Century-Crofts, 1972.

Kirk, R. E. Experimental design: Procedures for the behavioral sciences. Belmont, Calif: Brooks/Cole, 1968.

Morris, D. D., \& Smith, J. C. X-ray conditioned saccharin aversion induced during the immediate post-exposure period. Radiation Research, 1964, 21, 513-519.

Nachman, $M$. Learned taste and temperature aversions due to lithium chloride sickness after temporal delays. Journal of Comparative \& Physiological Psychology, 1970, 73, 22-30.

Razran, G. Mind in evolution. Boston: Houghton Mifflin, 1971.

Revusky, S. Aversion to sucrose produced by contingent x-irradiation: Temporal and dosage parameters. Journal of Comparative \& Physiological Psychology, 1968, 65, 17-22.

Rozin, P. Specific aversions and neophobia resulting from vitam in deficiency or poisoning in half-wild and domestic rats. Journal of Comparative \& Phy siological Psychology, 1968, 66, 82-88.

Rzoska, J. Bait-shyness: A study in rat behavior. British Journal of Animal Behaviour, 1953, 1, 128-135.

Scarborough, B. B., Whaley, D. L., \& Rogers, J. G. Saccharin avoidance behavior instigated by $x$-irradiation in backward conditioning paradigms. Psychological Reports, 1964, 14, 475-481.

Smith, J. C., \& Roll, D. L. Trace conditioning with $\mathrm{x}$-rays as an aversive stimulus. Psychonomic Science, 1967, 9, 11-12.

(Received for publication December 17, 1973; accepted January $21,1974$. ) 